\title{
Study of the Factors Affecting the Career Development of New-Immigrant-Children University Students in Taiwan
}

\author{
Chen Yu-Chuan ${ }^{1}$ \\ ${ }^{1}$ Department of Education, National Taiwan Normal University, Taipei, Taiwan R. O. C. \\ Correspondence: Chen Yu-Chuan, Department of Education, National Taiwan Normal University, Taipei, Taiwan R. \\ O. C. E-mail: a04001@ntnu.edu.tw
}

Received: September 6, 2019

Accepted: October 13, 2019

Online Published: October 16, 2019

doi:10.5430/ijhe.v8n6p192

URL: https://doi.org/10.5430/ijhe.v8n6p192

\begin{abstract}
Over the last two decades, Taiwan has experienced a surge in immigration due to marriage. With the growth in the incidence of international marriages, the number of immigrant children in Taiwan has sharply increased. Career development is an important factor worldwide and is thus an important issue for immigrant children in Taiwan. Many factors influence the choices of new immigrant children for their career development. The purpose of this study was to explore the factors influencing the career development of new immigrant children. The research was conducted using the qualitative research method, and data were collected from 30 participants who were new-immigrant-children university students. After analyzing the interviews of the participants, the results were analyzed. Further, on the basis of analysis of previous literature and interviews, recommendations were made for the career development of new immigrant children, such as strengthen the attainment of and respect for multi-culturalism through School, family, and social systems.
\end{abstract}

Keywords: career development, new immigrant children, Taiwan, university student

\section{Introduction}

With an increase in the number of international marriages, the number of immigrants in Taiwan has sharply increased. Many people living in Southeast Asia immigrate to Taiwan for marriage, and there has been a steady increase in the number of new immigrant children entering the local education system (Hsu \& Chiang, 2015). About a quarter of the women who immigrated to Taiwan in the 20th century and are now mothers came from Mainland China and Southeast Asian countries. Their children - new immigrant children — constitute a significant and growing proportion of those enrolled in Taiwan's schools. It has been estimated that such students make up over $10 \%$ of the domestic students in Taiwan from $\mathrm{K}$ to 12 . These children will grow up and enter Taiwanese universities and will play an important role in the development of Taiwan's economic future.

Over the last two decades, Taiwan has experienced a surge in immigration due to marriage. In the last 10 years, a large proportion of the married immigrants come from other countries, and dealing with their children has become an important social and economic issue for Taiwan. Many studies have explored the educational success of new immigrant children (Chen \& Chen, 2011; Huang, 2016), their interpersonal relationships and well-being (Chang \& Hsia, 2011), and related policies (Chang \& Hwang, 2007). With time, these new immigrant children grow up and enter universities and graduate from higher educational schools. Thus, career development has become an important issue for these children. However, immigration is a worldwide phenomenon, and immigrant culture could have some negative as well as positive impacts on these children. This topic needs to be explored further.

Career development is a worldwide concern and is thus an important issue for immigrant children in Taiwan too. Many factors influence the career decisions and choices of new immigrant children. According to Arayici (2003), the socio-educational and cultural problems affecting second- and third-generation immigrant children can be problems of those immigrant children in Europe. Against this theoretical background and taking into account additional research on career development, studies are often focused on or limited to explaining dichotomous career decision-making events, resoluteness, or career trajectories and career transitions of immigrant children (Fritsch, 2016: 622).

Therefore, the purpose of this study was to explore factors influencing the career development of new immigrant children in Taiwan. First, the available literature on new immigrant children and their career development is 
discussed. Then, the research methods employed in this study are described. Next, the empirical findings of this study are presented. Finally, the main conclusions are given and suggestions based on literature review and qualitative data, as well as practical implications for future studies are presented.

\section{Literature Review}

This literature review is organized into three main parts: "New immigrant children," "Career development," and "Relative research."

\subsection{New Immigrant Children}

Taiwan has seen large-scale immigration in the past. Most of the immigrants are females who come from Mainland China, Hong Kong, Macao, and Southeast Asian countries, such as Vietnam, Thailand, Indonesia, Malaysian, and Myanmar. A typical immigrant family would consist of a Taiwanese husband and Southeast Asian or Mainland Chinese wife. Their children are called "New immigrant children" in Taiwan.

Internationally, migration is a common feature of life. However, immigration in the West is different from that in Taiwan. The marriages between Taiwanese men and Southeast Asian or Mainland Chinese women are a different type of international marriages. Since the 1980s, many female immigrants who came from underdeveloped or backward countries married Taiwanese men and immigrated to Taiwan. These women might have been eager to marry Taiwanese men in order to create a better life for themselves in Taiwan. However, the Taiwanese families they marry into are often poor and underprivileged. They belong to socially vulnerable groups and need more attention from the society as a whole (Chang, \& Hsia, 2011; Chen, \& Chen, 2011; Hsieh, Cheng, Wang, \& Kuo, 2015).

In the past twenty years, new immigrant children who enter the elementary school and junior high school systems have become the fastest growing and the most extraordinarily diverse segment of Taiwan's children population. Although the percentage of new immigrant children has dropped a little in the last 10 years, new immigrant children still accounted for $5.87 \%$ of newborn babies $(194,616)$ in Taiwan in 2017. In other countries, such as USA, Canada, Japan, and England, this number is much lower (as low as 0.17\%) (Ministry of the Interior, 2019) (As shown in Table 1).

Table 1. Nationalities of newborn babies' mothers (\%)

\begin{tabular}{lllllllllll}
\hline \multirow{2}{*}{ Year Number } & Domestic & \multicolumn{2}{c}{ Other } & \multicolumn{3}{c}{ Mainland Hong Kong and } & \multicolumn{3}{c}{ Southeast } & \multicolumn{2}{c}{ Other } \\
& & & countries & China & Macao & & Subtotal & Asia & countries & \\
\hline 2008 & 196,486 & 90.37 & 9.63 & 4.91 & 0.05 & 4.96 & 4.55 & 0.11 & 4.67 \\
2009 & 192,133 & 91.34 & 8.66 & 4.57 & 0.07 & 4.64 & 3.92 & 0.10 & 4.02 \\
2010 & 166,473 & 91.29 & 8.71 & 4.84 & 0.08 & 4.92 & 3.66 & 0.14 & 3.80 \\
2011 & 198,348 & 92.21 & 7.79 & 4.45 & 0.08 & 4.52 & 3.14 & 0.12 & 3.26 \\
2012 & 234,599 & 92.64 & 7.36 & 4.21 & 0.09 & 4.31 & 2.93 & 0.13 & 3.05 \\
2013 & 194,939 & 93.29 & 6.71 & 3.79 & 0.08 & 3.87 & 2.71 & 0.13 & 2.84 \\
2014 & 211,399 & 93.79 & 6.21 & 3.61 & 0.09 & 3.70 & 2.36 & 0.15 & 2.51 \\
2015 & 213,093 & 93.86 & 6.14 & 3.30 & 0.10 & 3.41 & 2.58 & 0.15 & 2.73 \\
2016 & 207,600 & 93.90 & 6.10 & 3.20 & 0.12 & 3.31 & 2.64 & 0.14 & 2.79 \\
2017 & 194,616 & 93.96 & 6.04 & 2.79 & 0.15 & 2.94 & 2.93 & 0.17 & 3.10 \\
\hline
\end{tabular}

Data from: Ministry of the Interior (2019). Countries of origin of newborn babies' mothers. Retrieved from https://www.ris.gov.tw/app/portal/346

\subsection{Career Development}

A career is defined as the combination and sequence of roles played by a person during the course of a lifetime; these roles include everyone, including children, students, citizens, workers, spouses, homemakers, parents, and so on (Super, 1980). Career development is a significant factor in everyone's life, but it is a very complex process that is stimulated by the interactive effects of internal and external forces (Baldwin \& Blackburn, 1981: 602). Many of the personal factors and academic life skills that influence career success are trainable. Skills such as resilience and initiative can be taught, as can leadership and time management (Rubio, Robinson, Gabrilove, \& Meagher, 2017).

Rubio et al. (2017) indicated that career development includes five broad categories: (1) self-awareness, (2) selecting 
the right topic and securing funding, (3) getting adequate support, (4) working with others, and (5) managing yourself, your career, and your demands. The identity of the new-immigrant-children university students can be a positive or a negative influence on their career development. In Taiwan, there has been very little research on exploring this influence with the aim of understanding the identity of university students as it affects their career development.

\subsection{Relative Research}

Immigrant children is a popular topic. They have the subject of many studies (Cote \& Yuen, 2013; Fadnes, Møen, \& Diaz, 2016; Hällsten, Szulkin, \& Sarnecki, 2013; Kaplowitz, Perlstadt, Dziura, \& Post, 2016; Zhou, 1997). However, most of these studies have been conducted on immigrant children who are different from the "new immigrant children" in Taiwan. As mentioned previously, the mothers of new immigrant children come from specific countries that are less developed than Taiwan. However, with an increase in the number of new immigrant children, more and more studies are being conducted on these children in Taiwan.

Immigrant children are influenced by their parents. Jhang (2018) examined whether parents' education and students' previous achievements affected parental involvement and mediated differences in parental involvement between new immigrant and native parents in Taiwan. The results indicated that the association between immigrant status and parent-child discussion is partially mediated by parents' education rather than by students' prior achievements. This study proved that parents play important roles in children's development and suggested that new immigrants should be encouraged to return to school to narrow the immigrant-native gap in Taiwan.

Wu (2009) explored new immigrant children's cultural identification with their mothers' birth countries and with Taiwan. Most new immigrant children culturally identified well with their mothers. Chang (2018) investigated the factors affecting the cultural identity of Vietnamese new immigrant children and their attitude toward the Chinese and Vietnamese cultures. New immigrant children consider that their multicultural background gives them advantages in their career, such as their attractive appearance and some gifts from new immigrant events. Their mothers' nationality can influence these children's development, as Wu and Chang studied. The children of new immigrant women were scored lower in terms of home cultural capital, reading motivation, and reading behavior than the children of non-immigrant women (Chang \& Wang, 2012). The poor academic performance of new immigrant children is often attributed to their low level of intelligence and inadequate maternal parenting. The Taiwanese society often overlooks the sociocultural factors imposed on these children, thereby failing to recognize their potential learning advantages (Hsu, \& Chiang, 2015).

In early studies on this topic, new immigrant children were regarded as disadvantaged groups/communities. Hsieh et al. (2015) explored differences in academic performance in Mandarin between children from new immigrant families and nonimmigrant families. They found that the new immigrant children had significantly lower Mandarin and math scores than the nonimmigrant children did. Significant differences with large effect sizes existed between both groups' fourth-grade Mandarin scores and those of children from China, Hong Kong, Macao, and Southeast Asia. Significant differences also existed for sixth-grade scores. However, in today's Taiwanese society, the multicultural background of new immigrant children is useful for them, a departure from the past observations. New immigrant children identify with their mothers' culture. Wu (2009) stated, "Most immigrant brides' children's cultural identification with their mothers was well." Their cultural identification with their mothers will help them to immerse in the Taiwanese culture, and their identity can influence their career development. In summary, new immigrant children have been extensively studied, but only a few studies have focused on their career development.

\section{Methods}

\subsection{Research Design}

Over the last 20 years, qualitative research methods have gained popularity in the field of education research. In order to understand some complex areas, more qualitative research methods have been adopted. Interview is a useful way to collect data. In this study, interview was used to collect data from new-immigrant-children university students in Taiwan. The participants were interviewed by the researcher and research assistant together.

There are many factors that influence the career development of university students. In order to have an in-depth understanding of these influencing factors, interview was used to collect data from the participants. The interviews had a semi-structured outline. In order to contextualize the participants' family situation, they were first asked about their parents, family's financial condition, and siblings. Further, the semi-structured interview contained questions on education, career choice, parents' influences, and so on. Accordingly, the following research questions were asked:

How about your family or parents? Where does your mother come from? 
What will you do after graduation (pursue an advanced diploma or enter the workforce)? Why?

How does the image of "new immigrant children" influence your career development?

Whom will you ask for advice in the decision-making process?

What factors influence your career development (such as policy, system, family, education, culture, study experience, or education)?

What is your attitude in facing difficulties in career development? And what practical actions will you take?

Could you give some suggestions on how to help career development of new immigrant children?

Do you have any suggestions about this research?

\subsection{Participants}

The participants were all new-immigrant-children university students, 18 to 22 years old. This study uses snowball sampling to select interviewees. Their mothers were from Mainland China or other Southeast Asian countries, such as Thailand, Indonesia, Myanmar, Malaysia, and Vietnam. All of them had Taiwanese fathers. Eight participants were males, and 22 were females. Eighteen participants studied in public universities, and 12 studies in private universities (see Table 2).

Table 2. Participants based on their mothers' country of origin

\begin{tabular}{ccccccc}
\hline Mothers' country & Mainland China & Vietnam & Thailand & Indonesia & Malaysian & Myanmar \\
\hline Male & 2 & 3 & 0 & 1 & 1 & 1 \\
Female & 4 & 9 & 1 & 7 & 1 & 0
\end{tabular}

\subsection{Data Collection and Analysis}

This research was conducted using the qualitative research method. Interview is a technique widely used in qualitative studies. In this study too, interview was used to collect data from the participants. Interview is a conversational practice where knowledge is produced through the interaction between an interviewer and an interviewee (or a group of interviewees) (Brinkmann, 2014). Kvale and Brinkmann (2008: 3) stated that interview is a conversation that has "the purpose of obtaining descriptions of the life world of the interviewee in order to interpret the meaning of the described phenomena." In this study, interview was used to collect data.

Before the interview, they were given interview questions and asked to send their agreement through e-mail, phone, or social media. After obtaining permission, detailed information was given to the participants. Before the interview process, the participants were informed, for ethical purposes, that their interview will be recorded. Unauthorized audio recording during an interview process was strictly prohibited. Each interview lasted 50-120 minutes and was audio-recorded and subsequently transcribed. In addition, two peers reviewed transcriptions to avoid potential researcher bias. NVivo11.0 software package was used to manage the data and check for consistent application of codes. The first one and female of participants is F1 (F=Female), and second one/Male is M2, and so on.

\section{Study Results and Analysis}

After analyzing the interviews of 30 new-immigrant-children university students, researchers advanced the following study results and analysis:

4.1 Identity Approval Increases with Age and as One's Mother's Country Experiences Economic Prosperity, Which is Beneficial to Career Development

As mentioned in the above literature, from the perspective of a new immigrant family, the early period is somewhat negative. As the number of new immigrants and of their children increases, and as the acceptability of multi-culturism increases, new immigrant families do well integrating into society. However, there was still a small number of participants who stated that their mothers experienced discrimination in Taiwan, such as participants F1, F2, M5, and F15:

"My mom still feels that everyone discriminates against her. As long as she doesn't open her mouth, but as soon as she opens her mouth, it is very obvious that she is different from the Taiwanese. Like when my mom goes to a breakfast restaurant or something, she will be discriminated against by the restaurant boss."(F1)

"Mainly at elementary school and junior high school, the teacher likes to say in front of the other students, 'Where is this student from? ... Teachers think that if they say this, then the other students will look after us a little more, but in reality, as far as children are concerned, we are just foreigners." (F15) 
Most of the participants stated that they did not feel discriminated against, or perhaps as they got older, their own identity was more approved, especially as their mother's home country experience economic prosperity. This was most apparent for the children whose mothers came from the Chinese mainland. The mainland Chinese and Taiwanese cultures are both Chinese in nature, but for the mothers whose language was evidently not from southeast Asia, it was much easier for there to be cultural and language barriers. The recent economic boom in mainland China saw the identities of second generation new immigrants, as well as those of their mothers, be met with greater approval, thereby influencing the directions of their future careers. For example, a new immigrant whose mother came from mainland China (F7) thinks that those with dual identities can have dual approval, which is an advantage. Another participant (F4) graduated from college and then went on to mainland China for further education because "I have already been accepted to graduate school, so I will continue to take graduate studies. I think that that (mainland China) is a pretty good market, and I can make good use of it." This result and Wu's (2009) research are consistent with the approval levels of the cultures of new immigrant mothers.

"I think that to me, this dual identity is an advantage. I think that society actually needs a dual sense of approval. I don't really have an identity approval problem as a child of new immigrants." (F7)

"I think that I'm different from everyone else, and before I was more immature in my way of thinking. When I grew up, I thought that if it was being talked about and someone else had asked about it, that I would be willing to talk about it. I think that this identity is very advantageous for my learning." (F25)

"I don't think that this identity hindered my overall process of growing up. I think that their cultures from two countries influencing my process of growing up. Actually, it's not bad. Now that I've grown up, I think that I have a little more experience than other people. I think that after college I will probably start to feel like this identity is really awesome." (F26)

\subsection{Government Promotes New Southward Policy Subsidy, Expands the Range of Future Career Development}

In recent years, the government has promoted the New Southward Policy. In addition to the economic and cultural aspects, it also promotes related educational policies. As for the children of new immigrants, in view of families with a multi-cultural foundation and the advantages of having a mother from Southeast Asia, it provides children of new immigrants with educational opportunities in their mother's home country. As part of the New Southward Skill Development Plan promoted by the Ministry of Education, it will help children of new immigrants develop ASEAN languages and workplace practices. It will also subsidize children of new immigrants to use their summer holiday period to their mothers' homeland to participate in international workplace experience activities. Some of the participants of these interviews had attended the government assisted program to return to their mothers' homeland, and they expressed that this experience activity allowed them to gain a deeper understanding of the conditions of their mothers' home country and to have higher approval of their own identity. It also increased incentives to return to one's mother's homeland after college graduation for work or post-graduate studies, thereby expanding the range of career development.

"Every year, the city runs it, and we attended it last year. I think this is the third or fourth year? All second generation new immigrants can attend it. The activities are usually last from 7-14 days, and it's all free. I think that this is very good. It is run by the government, so it is free. By going to the activities, you can meet more people and expand interpersonal relationships. You really get a lot from it." (F2)

"One aspect is expanding one's own perspective, because to me, I have been in Taiwan since I was little. Most of my classmates did not have the same identity as me, and some did have a mother from another country. Before I had attended this program, I would never really pay attention to these types of issues. I had never cared about, what is the culture like where my mom came from? After attending these programs, I started to be more aware, and to think about whether my identity has something that I can make use of." (F7)

\subsection{Family Economic Situations are an Important Factor in Career Development, Even Greater than Identity}

After interviewing 30 university students who are children of new immigrants, it was discovered that the greatest factor affecting their career development was not the label of being the child of a new immigrant; rather, it was their family's economic situation. One interviewee (M3) mentioned that back when they were reading about the different university departments, they decided what to study based on which one would have a better effect on income after graduation, as opposed to emphasizing their own learning interests. Interviewee (F4) thinks that identity did not affect them very much; instead, their family economic situation was the greatest obstacle to career development: "Because I think that encountering obstacles has more to do with being poor." Participant (F23) stated that being able to turn their family's economic situation is a main factor when selecting a course of study. 
"To tell the truth, if your family income is not high, your career selection will be more practical. Just like I am studying business administration, which is an example of practicality. I think that income is the main thing." (F4)

"Family economics probably have a big influence. Like my mom, actually ever since I was in high school, she started letting me take time off of school to work. She doesn't think that studying is really that important; she thinks that making money is more important. My parents have two children, me and my brother. It's the same, mom tells us to quickly go out and earn some money, then come home and give it to the family." (F8)

Overall, throughout the course of these interviews, most participants thought that having an identity as a child of new immigrants did not affect them greatly. The greater influence came from the family economic situation. Out of the students who were interviewed, many of them were studying at national universities. This shows that they performed fairly well academically in high school, otherwise they would not be able to study at a national university. However, they still had to consider their family's economic condition when selecting a course of study. Being able to turn their families' economic situation became an important factor when choosing majors, leading the direction of career development. Like the situations brought up by participants (M6, M23), this is the best example of the family's economic condition affecting career development. Studies by Wu, Chang Wang (2007) show that a greater percentage of new immigrant families face economic crises, and this is an area that needs greater attention by the government.

"My mom still earns less; it's still mostly my dad. And higher education will not necessarily let you change your family's circumstances, to make your family's life a little bit better." (23)

"It's about selecting one from within your interests that will have a decent income in the future. You might have 3 or 4 interests, so you select the one with the highest income out of those 3 or 4." (M6)

4.4 Universities Provide a Special Admissions Pipeline, Opening Different Study Experiences for Children of New Immigrants

In Taiwan, the question of which ethnic groups should be considered "vulnerable" is always a topic of expert and political controversy. Should children of new immigrants be listed as vulnerable? Should they be given subsidies similar to aborigine students? These questions are still debated today. While over $90 \%$ of those we interviewed supported listing the children of new immigrants as vulnerable and providing them with subsidies, some people responded by saying that universities already have a set special talent selection pipeline which have increased the admissions access for children of new immigrants. Throughout the course of these interviews, there were participants who obtained better university enrollments due to their identity (children of new immigrants). These same students unequivocally stated that they would never have been enrolled in this type of university and major if they had used a regular admissions pipeline.

"At that time, xx University had an admissions pipeline for children of new immigrants and they provided five volunteers, so I prioritized that one. When I was little, I wanted to be a teacher, so I wanted to major in literature. I didn't test well in literature, but I really wanted to go to xx University. So I gave it a shot and applied, and I ended up getting in. I don't think I would have gotten in if I had relied on normal grades." (F10)

In this example, the student was able to study their desired major and realize their aspiration of becoming a teacher due to the multiple talent selection pipelines. For students who are children of new immigrants, this can unfold different study experiences and can be a turning point which affects their career development.

\subsection{Unpleasant Study Experiences Become Inspiration for Upward Progress, Affecting Career Development}

Many of the interviewees were students from national universities. In Taiwan, going to a national university means that their academic situation was fairly good. But how many of these students, throughout the course of their learning process from a young age, have been discriminated against by those around them? How many of them have made children of new immigrants feel hurt because of their identity, or because of how the teacher speaks, or because of their treatment by fellow students? Yet, those who refuse to admit defeat and study even harder are able to improve their grades. This also affects their future, as they are able to study at a university and unfold a new career development.

"Because you have been discriminated against, you tell yourself that you have to work harder, you must have the highest or second highest test score, and you must get 100 on the tests. ...However, right before our graduation ceremony, I don't know why but a lot of people suddenly knew that my mom was Indonesian. And there was a female classmate who, although I don't think it was with ill intentions, said something that hurt me. She said, 'Your mom is Indonesian?' I said, 'Yes, my mom is Indonesian.' She said, 'But your grades are really good.' What does that mean?" 
(F1)

"I have taken remedial classes after school, and actually I think that remedial classes have a big influence on us. More importantly, I met some other children of new immigrants there or classmates from more dysfunctional families. Saying it this way is a little over the top, but afterwards I didn't want to become like them, I didn't want to be poor like them. So you think to yourself, I have to work hard to separate myself from that kind of condition." (F2)

\subsection{The Cultural Differences between Identities Can Expand Career Horizons and Create Different Experiences}

The author asked 30 university students who are children of new immigrants if their mothers created a cultural difference, and most felt that there was no obvious difference. Of the small number of them thought that there was a difference, more of them viewed it positively than negatively. The majority of the interviewees thought that having a mother from another country helped expand their horizons and create different experiences, indirectly or directly affecting their future career development. With this being the case, they are not classified as having cultural differences. In terms of the effects, children of new immigrants think that having a mother from another country allows them to have more opportunities to engage in different cultures, expand their horizons, and affects where they might choose to work or continue their education. Such as the interviewee (F13) stated that different experiences and understanding of other countries can give them more opportunities to learn different languages and cultures.

"Because this identity has a lot to do with this issue, I would want to become familiar with that culture. I think that one's perspective would change." (F9)

"I think that there will be a certain amount, because you will hear your mom talk about things from there. But I think that even more than this is that I think we might be more empathetic than others. Because we are different, so we can know what the other side is thinking." (F10)

"I think that it is also empathy, because when I was little I was in Vietnam more often. When I was growing up, I heard my mom speaking. But these experiences made me want to find some other paths, such as volunteering. Like last year I went to Myanmar and this year I am preparing to go to Hoping." (M11)

In addition to expanding horizons, the identity and experiences of children of new immigrants can add to or make good use of the learning process. For example, interviewee (F10) stated that this kind of identity and experience allowed them to choose the direction of the composition for their recent research project. Perhaps it is because they have deeper feelings and are able to have a deeper level of compassion and understanding that they can achieve good grades.

"I still hesitate quite a bit, because of my dad. And when my mom was little she couldn't communicate well because of the language, so I never felt family warmth even a little bit. But because I am studying literature, the research project that I wrote has to do with new immigrants, and I got a good grade on it." (F10)

4.7 Teachers and Parents are the Main Factors in Providing and Influencing the Career Planning of Children of New Immigrants

In addition to looking for external resources and support, most participants said that their parents and teachers influenced them the most when they encountered career development problems, providing them with people to help them plan strategies. For some of them, their moms did not have an adequate understanding of Taiwan, so their fathers were their primary source of information:

"When I was preparing for college, my dad gave me advice. On the other hand, my mom wasn't able to give my any advice because she didn't grow up in Taiwan. When it came to things like conditions at specific universities or social opinion on a certain university, she couldn't understand them as deeply as a Taiwanese person. So she wasn't able to give me a lot of advice." (F14)

"When I encountered difficulties with assignments, my dad would teach me math when I was little. That was around first or second grade, so it was a long time ago." (F28)

For children of new immigrants, if their parents are unable to provide assistance, teachers can also be important consultants. Interviewee (M23) said that teachers helped them obtain information and assistance: "When I was in high school, teachers gave me some direction and some information about scholarships" (M23). This kind of assistance often affects a student's future career development, as studies by Wu, Chang, Wang (2007) point out: schools and teachers should care even more for children of new immigrants, while family support also plays an important role. 


\section{Conclusion and Suggestions}

Analysis of the preceding literature and interviews have resulted in the following conclusion and suggestions for our study:

\subsection{Conclusion}

Children of new immigrants are special ethnic group in Taiwan. As they grow up, to study of the factors affecting the career development become important topics. At present, there are not many studies about this topic, and show the importance of this study. After analyzing the contents of the interviews from 30 college students who are children of new immigrants, the following results were obtained: the identity approval for new-immigrant-children increases as they age and as their mother's native country experiences economic prosperity. This affects their future career development and planning. Throughout this process, the government has provided subsidized activities under the New Southward Policy. Founded on the basis of multi-cultural families and the advantage of having a mother from a Southeast Asian country, it allows children of new immigrants to attend activities from their mother's home country. These experiences and activities help them to understand the conditions of their mothers' native country, and there has been a great increase in their desire to return to those countries for work or postgraduate studies.

Throughout the course of the interviews, it was discovered that the family economic situation was the main factor affecting the career development of children of new immigrants. Its influence was even greater than their identity classification. Most of the participants felt that their identity as a child of new immigrants did not affect them very much; rather, they felt that their family's economic situation produced a greater effect. In addition, universities currently have special talent acquisition pipelines that provide a specialized means of admission, thereby opening the door to different academic experiences for children of new immigrants. This helps in being accepted for the more prestigious majors for students whose academic performance would otherwise make them unable to do so, thereby having a great influence on their career development. There remains a small percentage of university students who are children of new immigrants who have been discriminated against throughout the course of their studies. This has affected their career development by providing them with even more motivation to strive for success. For them, they can view the cultural differences stemming from their identity classification positively, as they feel that this kind of difference can expand their career horizons and help them to have different experiences.

Overall, all of the participants in this study were children of new immigrants and were all college students, meaning that they had fairly good academic performance. As they identify as children of new immigrants, they are more familiar with accessing government resources. Throughout the course of their studies, teachers and parents are the main human factors affecting their career development as children of new immigrants. For most of these students, parents and teachers were their greatest sources of support when they encountered career development problems, providing them with helpful strategies. At last, this research is a qualitative study and it has its limitations. In the future, researchers can consider quantitative research and conduct more extensive data collection as a reference for the formulation of educational policies.

\subsection{Suggestions}

Analysis of the literature and interview data have resulted in the following suggestions concerning this study:

Establish a database and inter-departmental data to analyze performance after higher education

The establishment and use of a database is already a very popular trend in the academic and practical worlds. Databases in educational fields are primarily funded by the Ministry of Education because without public authority, it would be difficult to basic level academic data. Previous databases for higher education have already stopped receiving data and there is no data in them that can be distinguished as concerning children of new immigrants. The databases which are still gathering data - such as the Taiwan Later Era Secondary Education Long-Term Tracking Database, the Taiwan Teacher Development Database, the Infant Development Survey Database, and the Special Education Long-Term Tracking Database - do not have 'children of new immigrants' as a background variable. Moreover, inter-departmental data can be linked to provide cross-analysis on the income, academic conditions, graduation salaries, etc of children of new immigrants, in order to more deeply understand their performance status and life needs.

Some databases, such as the Taiwan Later Era Secondary Education Long-Term Tracking Database, have begun installing a background variable for 'children of new immigrants', which allows for distinguishing conditions for children of new immigrants. It also allows for simple analysis topics, such as the number of children of new immigrants at high-level secondary schools in the 2016 academic year, the number of children of new immigrants at high-level secondary schools in the 2015 academic year, and the number of children of new immigrants as freshmen 
students at vocational schools for the years 2012-2016. However, these databases still lack deeper statistical analysis in order to understand the educational and life conditions for children of new immigrants. Therefore, it is the researchers' recommendation that more options for the identity classification as children of new immigrants be added to existing databases, and after conducting data collection, that researchers be funded to perform statistical analysis on the data. Yet in the process of providing funding, they must overcome the obstacle of the inter-departmental committee struggling to use the data while the databases surpass national capital.

Provide economic assistance based on family economic situation, not based on identity, in order to reduce labeling

Are children of new immigrants vulnerable? Throughout the course of these interviews, more than $80 \%$ of the participants (children of new immigrants) expressed that the assistance for children of new immigrants is decidedly a good thing. However, they would be happy to see the allowance changed to being determined not by identity, but rather by the family economic situation, as this way, children of Taiwanese parents and children of new immigrants would all be treated equally. Researchers have discovered from their studies on vulnerable college students that the funds for many activities at universities are tied to identity classification assistance methods. Many universities encounter problems with poor attendance at these activities or struggle to cancel the events.

Throughout these interviews, many of the families were fairly well off. For these families, the parents were married when the father went to the mainland for work. For categorization purposes in Taiwan, they are still children of new immigrants and there are still social stereotypes about them. For them, being 'children of new immigrants' is not a sign of weakness, nor does it mean that they need assistance. As their mothers' countries flourish economically, the multi-culturalism and broadened future career options for these families become an advantage.

Strengthen the attainment of and respect for multi-culturalism through School, family, and social systems

Throughout the course of interviews, there were some children of new immigrants who felt that their fellow citizens were friendly toward them. However, there are still some incorrect and biased concepts. The culture of their mothers' native countries are viewed with the attitude of 'assimilation', whereas Taiwanese culture is seen as the mainstream. Actually, the children of new immigrants don't think that cultural factors will affect their career plans because under the mainstream Taiwanese culture, the culture of the mother's home country is not given any voice to the point of being disregarded and neglected. If there is an influence, it is mainly limited to their diet. However, the mother's native culture being seen as secondary or in need of being assimilated under current multi-cultural concepts is truly a mistake. To this end, strengthening the attainment of and respect for multi-culturalism through schools, families, and social systems is all the more important.

Continuing to provide university students with overseas study opportunities, assisting them in understanding the culture of their mother's native country

In terms of the factors affecting the career planning for children of new immigrants, the participants thought that in addition to helping them further understand the culture of their mothers' native country, having previously visited that country also gave them more motivation to choose to work in a foreign country. For example, during these interviews, "one participant confirmed that the government-sponsored activities allowed them to more deeply understand their own identity and to form different opinions about different fields. In recent years, the government has pushed the Southward Policy. After mainland China, most of the new immigrants hail from Southeast Asian countries, which allows the children of new immigrants to make use of government resources, such as attending activities, language classes, and broadening their horizons. These are certain to have a great influence on their career plans." In short, making use of government-sponsored resources can expand not only the horizons but also the career selectivity of children of new immigrants.

Learning and adaptation follow-up surveys should be conducted for university students admitted based on identity classification

Whether or not children of new immigrants should be classified as vulnerable has always been controversial with no general consensus being reached. And yet, there are many universities with special talent acquisition pipelines which have served as a new means of admission for children of new immigrants. In the course of these interviews, there was an example of a student who obtained better college admissions due to their identity classification. This student unequivocally relate that if they had used a normal admissions pipeline, they would have been unable to be admitted to their current school and major.

For the time being, we will not discuss whether or not students being admitted to college based on their identity classification is in keeping with social equity and justice. However, we did find from the interviews that when there is only a small gap between the student levels for children of new immigrants and admissions to schools and majors, 
there are no major problems with their learning and adaptability. But for those who do have a big gap, there usually are major problems with their learning and adaptability. Therefore, just as obtaining college admissions opportunities based on identity classification has become an established government policy, this research team recommends that the learning and adaptability of these students should be tracked with follow-up surveys after enrollment. Corresponding guidance measures should be advanced in order to increase their success in learning and in adapting to life.

\section{References}

Arayici, A. (2003). The problems of immigrant children in Europe: The case of the Turks. Prospects, 33(4), 453-466. https://dx.doi.org/10.1023/B:PROS.0000004615.28768.12

Baldwin, R. G., \& Blackburn, R. T. (1981). The academic career as a developmental process. The Journal of Higher Education, 52(6), 598-614. https://doi.org/10.1080/00221546.1981.11778133

Brinkmann, S. (2014) Interview. In: Teo T. (eds) Encyclopedia of Critical Psychology. New York, NY: Springer.

Chang Y. T. (2018). Standing on the cross-cultural edge: The history education and cultural Identity of the new residents' children in junior high school. Chung Yuan Christian University, Graduate School of Education, Master's thesis.

Chang, C. Y., \& Hwang, J. J. (2007). Prospects of education for Taiwan new immigrant children-The reconstruction of multicultural education. Curriculum \& Instruction Quarterly, 10(1), 1-19. https://doi.org/10.6384/CIQ.200701.0001

Chang, F. C., \& Hsia, L. F. (2011). A study on interpersonal relationships and well-being for immigrant children. Journal of Education of NCUE, 20, 73-101. https://doi.org/10.6769/JENCUE.201112.0073

Chang, F. C., \& Wang, P. K. (2012). A study on family cultural capital, reading motive and behavior of children of new-immigrant women and non-new-immigrant women. Journal of National Taichung University of Education, 26(1), 55-89. https://doi.org/10.7037/JNTUE.201206.0055

Chen, Y. L., \& Chen, S. M. (2011). The study of high academic achievement students of new immigrant children. School administration, 76, 89-109. https://doi.org/10.6423/HHHC.201111.0089

Cote, L. R., \& Yuen, C. X. (2013). Children abroad: Immigrant children's development in worldwide perspective. Human Development, 56(1), 76-81. https://dx.doi.org/10.1159/000342934

Dept. of Household Registration (2018). Mothers' countries of newborn babies. Taiwan, Taipei city: Ministry of the Interior, R. O. C. Retrieved from https://www.ris.gov.tw/app/portal/346

Fadnes, L. T., Møen, K. A., \& Diaz, E. (2016). Primary healthcare usage and morbidity among immigrant children compared with non-immigrant children: A population-based study in Norway. BMJ Open, 6(10), 1. https://dx.doi.org/10.1136/bmjopen-2016-012101

Fritsch, N. (2016). Patterns of career development and their role in the advancement of female faculty at Austrian universities: New roads to success? Higher Education, 72(5), 619-635. https://dx.doi.org/10.1007/s10734-015-9967-6

Hällsten, M., Szulkin, R., \& Sarnecki, J. (2013). Crime as a price of inequality: The gap in registered crime between childhood immigrants, children of immigrants and children of native Swedes. British Journal of Criminology, 53(3), 456-481. https://0-doi.org.opac.lib.ntnu.edu.tw/10.1093/bjc/azt005

Hsieh, P. J., Cheng, C. M., Wang, R. J., \& Kuo, K. B. (2015). Large-scale survey of the elementary school mandarin achievements of children from new-immigrant families. Journal of Research in Education Science, 60(4), 93-127. https://doi.org/10.6209/JORIES.2015.60(4).04

Hsu, C. T., \& Chiang, T. H. (2015). Education policies for children of new immigrants formulated for increasing human capital and strengthening international competitiveness. Journal of National Chiayi University, 34, 25-59.

Huang, Y. C. (2016). The analysis of educational attainment and learning attitude of second-generation immigrants and mothers with Taiwanese nationality. School administration, 101, 201-219. https:// doi.org/10.3966/160683002016010101011

Jhang, F. H. (2018). Explaining the immigrant-native gap in parental involvement in Taiwan: The role of parents' education and students' prior achievement. Asia Pacific Education Review, 1-13 (online). 
https://dx.doi.org/10.1007/s12564-018-9555-4

Kaplowitz, S. A., Perlstadt, H., Dziura, J. D., \& Post, L. A. (2016). Behavioral and environmental explanations of elevated blood lead levels in immigrant children and children of immigrants. Journal of Immigrant and Minority Health, 18(5), 979-986. https://dx.doi.org/10.1007/s10903-015-0243-8

Kvale, S., \& Brinkmann, S. (2008). InterViews: Learning the craft of qualitative research interviewing. Thousand Oaks, CA: Sage.

Ministry of the Interior (2019). Countries of origin of newborn babies' mothers. Retrieved from https://www.ris.gov.tw/app/portal/346

Rubio, D. M., Robinson, G. F. W. B., Gabrilove, J., \& Meagher, E. A. (2017). Creating effective career development programs. Journal of Clinical and Translational Science, 1(2), 83-87. https://dx.doi.org/10.1017/cts.2016.30

Super, D. E. (1980). A life-span, life-space approach to career development. Journal of Vocational Behavior, 16(3), 282-298. https://doi.org/10.1016/0001-8791(80)90056-1

Wu, C. J. (2009). The cultural identification of the immigrant brides' children: The example of junior high school students in Yunlin country. Journal of National Taichung University of Education, 23(2), 187-204. https://doi.org/10.7037/JNTUE.200912.0187

Wu, J. X., Chang, M. Y., \& Wang, S. T. (2007). The education issues of the "new inhabitants' children"-A viewpoint based on children's learn rights. School Admonition, 50, 269-281. https://doi.org/10.6423/HHHC.200707.0269

Zhou, M. (1997). Growing up American: The challenge confronting immigrant children and children of immigrants. Annual Review of Sociology, 23, 63-95. Retrieved from https://search.proquest.com/docview/60067339?accountid=14228 